\title{
Kernos
}

Revue internationale et pluridisciplinaire de religion grecque antique

22 | 2009

Varia

\section{Jan N. Bremmer, Greek Religion and Culture, the Bible and the Ancient Near East}

\section{Vinciane Pirenne-Delforge}

\section{OpenEdition \\ Journals}

\section{Édition électronique}

URL : http://journals.openedition.org/kernos/1828

DOI : 10.4000/kernos. 1828

ISSN : 2034-7871

\section{Éditeur}

Centre international d'étude de la religion grecque antique

\section{Édition imprimée}

Date de publication : 1 janvier 2009

Pagination : 342-343

ISSN : 0776-3824

\section{Référence électronique}

Vinciane Pirenne-Delforge, « Jan N. Bremmer, Greek Religion and Culture, the Bible and the Ancient Near East », Kernos [En ligne], 22 | 2009, mis en ligne le 15 septembre 2011, consulté le 21 septembre 2020. URL : http://journals.openedition.org/kernos/1828 ; DOI : https://doi.org/10.4000/kernos.1828

Ce document a été généré automatiquement le 21 septembre 2020.

Kernos 


\title{
Jan N. Bremmer, Greek Religion and Culture, the Bible and the Ancient Near East
}

\author{
Vinciane Pirenne-Delforge
}

\section{RÉFÉRENCE}

Jan N. BREMMER, Greek Religion and Culture, the Bible and the Ancient Near East, Leiden/

Boston, Brill, 2008. 1 vol. 16,5 監 24,5 cm, 424 p. (Jerusalem Studies in Religion and Culture, 8). ISBN : 978-90-04-16473-4.

1 Cet ouvrage s'inscrit dans la tradition bien établie des Kleine Schriften, rassemblant en 15 chapitres des articles déjà publiés. Toutefois, l'A. n'a pas versé dans la facilité d'une simple reproduction à l'identique: la mise à jour rigoureuse de ces études, parfois profondément revues, fait de l'ensemble une précieuse mine d'information sur chacun des sujets abordés. De plus, le fil conducteur de tous ces chapitres réside dans un questionnement systématique sur les relations entre représentations mythiques et rituels grecs, et les traditions proche-orientales, en ce comprise la tradition judéochrétienne, ainsi que l'atteste le titre du recueil. Il ne s'agit donc pas d'une simple juxtaposition de circonstance.

2 Sans entrer dans le détail de chacun des textes, disons que la plupart des sujets d'analyse se prêtent particulièrement bien à l'exercice de la comparaison : les mythes de création (chap. 1), Ève et Pandora (chap. 2), la naissance du Paradis (chap.3), les crimes fratricides (y compris à Rome) (chap. 4), Kronos, les Titans et les combats entre puissances divines (chap. 5), les traditions du déluge (chap. 6), Eurydice et la femme de Lot (chap.7), les devins itinérants (chap. 8), la question du rapport entre l'hébreu lishkah et le grec leschè (chap. 9), l'expulsion du bouc-émissaire (chap.10), les révélations divines comme «rencontres du troisième type » vécues notamment par Héliodore et saint Paul (chap. 11), le mythe de la toison d'or (chap. 15). La comparaison 
à l'œuvre dans ces analyses, toujours respectueuses des contextes, est régulièrement assortie de la conviction d'une influence à l'œuvre derrière les ressemblances, à l'instar des approches de W. Burkert et de M. West. Toutefois, à quelques exceptions près, les canaux par lesquels des motifs mythiques ou des rituels auraient traversé la mer Égée restent mal connus, et les processus à l'œuvre dans la transmission et dans l'adaptation échappent. Par quelle(s) voie(s) les poètes grecs ont-il eu connaissance des traditions proche-orientales ? Par quelle voie des rituels ou des noms se sont-ils frayés un chemin vers la Grèce? L'espace ouvert aux hypothèses reste fort large et le caractère opératoire de l'explication par l'origine s'en trouve limité.

C'est évidemment dans la pluralité des regards et des méthodes que résident la richesse et l'intérêt de la recherche sur les problèmes posés par l'histoire religieuse antique : je suis de ceux qui considèrent que connaître l'origine d'un dieu ou d'un motif mythique si tant est que ce soit possible - restera toujours secondaire, en terme de portée et de signification, par rapport à l'analyse fine des modalités de son appropriation et de son intégration dans la culture qui le reçoit. Il est donc un petit nombre d'analyses où, tout en saluant la largeur de vue de l'enquête, le sceptique reste au bord du chemin. C'est notamment le cas du chapitre 13, qui pose le problème de l'origine du nom d'Asclépios, au départ d'une réflexion sur le culte d'Apollon Aiglètès sur l'île d'Anaphè, dont l'étiologie se trouve dans les Argonautiques d'Apollonios de Rhodes.

La question de la magie reçoit un traitement particulier puisqu'elle apparaît à la fois dans le chapitre 12, qui se penche sur l'origine perse du terme et son cheminement en Grèce et à Rome, et l'appendice II qui inscrit la polarité «magie - religion» dans l'historiographie du $\mathrm{XIX}^{\mathrm{e}}$ siècle. Il faut également mettre en exergue le remarquable chapitre sur Attis, publié en 2004 dans la revue Mnemosyne: il s'agit d'une véritable petite monographie sur cette figure à la croisée de l'Asie Mineure, de la Grèce et de Rome, qui est exemplaire de la méthode de travail rigoureuse de l'A. et de la manière limpide dont il pose les problèmes. Soulignons encore le beau chapitre sur le boucémissaire, qui rassemble trois études antérieures, dont le Scapegoat rituals in ancient Greece qui avait fait date (l'article a paru en 1983 dans les Harvard Studies in Classical Philology) et fut repris dans les Oxford Readings in Greek Religion édités par Richard Buxton en 2000. L'ensemble est très soigneusement édité, avec une bibliographie foisonnante et un excellent index.

\section{AUTEURS}

\section{VINCIANE PIRENNE-DELFORGE}

F.R.S.-FNRS - Université de Liège 